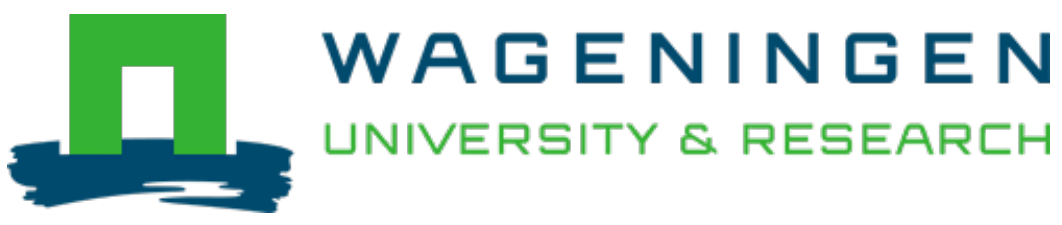

\title{
Genetic diversity and the reintroduction of meadow species
}

Plant Biology

Smulders, M.J.M.; Schoot, J.; Geerts, R.H.E.M.; Antonisse-de Jong, A.G.; Korevaar, H. et al https://doi.org/10.1055/s-2000-6780

This article is made publicly available in the institutional repository of Wageningen University and Research, under the terms of article $25 \mathrm{fa}$ of the Dutch Copyright Act, also known as the Amendment Taverne. This has been done with explicit consent by the author.

Article $25 \mathrm{fa}$ states that the author of a short scientific work funded either wholly or partially by Dutch public funds is entitled to make that work publicly available for no consideration following a reasonable period of time after the work was first published, provided that clear reference is made to the source of the first publication of the work.

This publication is distributed under The Association of Universities in the Netherlands (VSNU) 'Article 25fa implementation' project. In this project research outputs of researchers employed by Dutch Universities that comply with the legal requirements of Article $25 \mathrm{fa}$ of the Dutch Copyright Act are distributed online and free of cost or other barriers in institutional repositories. Research outputs are distributed six months after their first online publication in the original published version and with proper attribution to the source of the original publication.

You are permitted to download and use the publication for personal purposes. All rights remain with the author(s) and / or copyright owner(s) of this work. Any use of the publication or parts of it other than authorised under article $25 \mathrm{fa}$ of the Dutch Copyright act is prohibited. Wageningen University \& Research and the author(s) of this publication shall not be held responsible or liable for any damages resulting from your (re)use of this publication.

For questions regarding the public availability of this article please contact openscience.library@wur.nl 


\title{
Genetic Diversity and the Reintroduction of Meadow Species
}

\author{
M. J. M. Smulders, J. van der Schoot, R. H. E. M. Geerts, A. G. Antonisse-de Jong, H. Korevaar, \\ A. van der Werf, and B. Vosman \\ Plant Research International, Wageningen, The Netherlands
}

Received: December 2, 1999; Accepted: May 23, 2000

\begin{abstract}
Restoration of formerly nutrient-poor and speciesrich grasslands generally leads to an increase in species diversity. However, species without a persistent seed bank and with poor dispersal ability often do not re-establish spontaneously. Here, reintroduction is an option. If existing populations are comparable in their genetic composition, any population will do. This is not the case if populations have local adaptations. Unfortunately, whether populations are adapted locally is not easily determined, in contrast to assessing differentiation using neutral genetic markers. We used AFLP to study genetic diversity of Cirsium dissectum and Succisa pratensis within and among several Junco-Molinion plant communities in the Netherlands (up to $200 \mathrm{~km}$ apart) that were potential source populations, and followed the reintroduction using seeds from these populations. Also, vegetative growth phase characteristics of three populations of $C$. dissectum were analyzed under controlled conditions. Most of the genetic variation in these cross-fertilizing species was found within populations. Small but significant genetic differences in band frequencies were found among populations $\left(F_{s t} 0.100-0.135\right)$. The first generation of reintroduced plants contained less polymorphic bands than the source populations. The genetic differences caused by reintroduction using a limited number of seeds (founder effects) were significant in all except one case $\left(\mathrm{F}_{\mathrm{st}}\right.$ 0.012-0.101 between source and corresponding reintroduced population), but the magnitude was smaller than the source population differentiation. In assignment tests, reintroduced populations resembled their source population more than any other population, but all populations contained sizeable proportions of plants that were assigned to most similar plants from other populations, indicating that the populations are only marginally distinct. Calculations show that reintroduction from more than one source population introduces significantly more polymorphic bands into the new population, capitalizing on the existence of band frequency differences among populations.
\end{abstract}

Key words: AFLP, Cirsium dissectum, genetic diversity, Succisa pratensis, restoration ecology.

Plant biol. 2 (2000) 447-454

(c) Georg Thieme Verlag Stuttgart · New York

ISSN 1435-8603

\section{Introduction}

Due to intensive use of fertilizers, the species richness of grasslands in the Netherlands has greatly decreased during recent decades (Berendse et al., 1992 ${ }^{[2]}$ ). Restoration of formerly nutrient-poor species-rich grasslands involves a range of measures, including cessation of fertilization, removal of nutrients by haymaking or sod removal, and raising of the groundwater table (Oomes et al., 1996 ${ }^{[17]}$ ). These management practices generally lead to a strong decrease in annual biomass production and nutrient availability, and to an increase in species diversity. However, many species known to have been present in these grasslands do not re-establish spontaneously after a period of restoration (Prins et al., 1998 ${ }^{[19]}$ ). Geerts et al. $\left(1995^{[5]}\right)$ compared the species composition of typical JuncoMolinion communities with that of grasslands at the experimental site "De Veenkampen" near Wageningen, The Netherlands, that had been taken out of production 20 years ago. Even though species richness had greatly increased in these 20 years, typical species like Briza media, Gymnadenia conopsea, Cirsium dissectum, Linum cartharticum and Succisa pratenis had not re-established. An analysis of seed characters showed that only $22 \%$ of all species that were present in the 1940 s and that were absent after 20 years of restoration, have a persistent seed bank. They concluded that the absence of a persistent seed bank, in combination with the rather isolated position within a grassland area under intensive management, is the main factor for the absence of many of the now rare species. To accelerate the restoration of species-rich grasslands, active reintroduction of seeds is considered of paramount importance (Geerts et al., 1995 ${ }^{[5]}$; Pywell et al., 1997 ${ }^{[20]}$; Prins et al., $\left.1998^{[19]}\right)$.

When considering reintroduction, plants or seeds have to be collected from existing populations elsewhere. If populations have local adaptations, using one population or another is not equivalent. Material from a local source, e.g., a nature reserve nearby, may have the genetic composition of an environmentally similar site (Jones and Hayes, 1999[10]), and would therefore be an obvious choice for reintroduction. Material from elsewhere may have a lower fitness at the reintroduction site, and mixing of populations may result in outbreeding depression. However, if populations of a particular species are comparable in their genetic composition for traits important for adaptation and fitness, any population would do. In this situation, obtaining a sufficient amount of genetic diversity in the 
newly constructed population is an important goal, since it is essential for the long-term survival of the species (van Groenendael et al., 1998 ${ }^{[9]}$; Booy et al., 2000 ${ }^{[3]}$ ). Therefore, if remaining populations have lost genetic diversity through genetic drift and inbreeding because of fragmentation and isolation (van Groenendael et al., 1998 ${ }^{[9]}$ ), reintroduction should not be limited to material from a single, local population. Whether populations have adapted locally will depend on several factors, and is not easily predicted. Jones and Hayes $\left(1999^{[10]}\right)$ found that, for some species, the performance of locally collected seed with respect to seedling establishment was superior, in other species, however, material from more than $220 \mathrm{~km}$ away performed better. Unfortunately, measuring adaptation to local conditions is labourious. Usually, it is done by reciprocal transplant experiments, but the characters responsible for this local adaptation are largely unknown (Nagy, 1997[16]). Moreover, adaptation may become visible only under infrequent or extreme conditions (Jones and Hayes, 1999[10]). The demonstration of local adaptation is by no means universal in reciprocal transplant studies, and local adaptation may be relevant primarily to wide-ranging species occupying sites that clearly vary in climate, soil, etc. (Helenurm, $\left.1998^{[12]}\right)$. An alternative is to measure genetic differences between plants within and among possible source populations, to determine whether these populations consist of genetically distinct genotypes, using neutral molecular markers. Relatively few studies of plant species have combined measures of selection and genetic population differentiation (Hamilton, 1997[11]).

We conducted an experiment in which seeds of Cirsium dissectum and Succisa pratensis were collected from isolated speciesrich grasslands in the Netherlands and reintroduced in the restored grassland of the "Veenkampen" near Wageningen. One of the populations was located only a few kilometers from the reintroduction site, the others were randomly spread across the country. The maximum distance from the reintroduction site was less than $200 \mathrm{~km}$, with no major discontinuity in species presence other than $6 \mathrm{~km}$ of sea. We analyzed genetic variation within and among populations before and after reintroduction, using AFLP. The fragments produced by AFLP are generally from non-coding DNA and presumed to be selectively neutral. Moreover, together they represent a sampling of loci throughout the genome (e.g. Smulders et al., 2000[22]). In addition, some ecological relevant traits of the vegetative growth phase of plants from three grasslands of $C$. dissectum were analyzed under growth chamber conditions (sensu Grime and Hunt, $1975^{[8]}$; Lambers et al., 1998 ${ }^{[14]}$ ). With these data, we address the following questions: How much genetic variation is present within and among populations of $C$. dissectum and $S$. pratensis, does the genetic composition of a population shift upon reintroduction, and do the populations consist of genotypes that are distinct from other populations? For $C$. dissectum we also determine whether genetic differences coincide with ecophysiological differences among populations. Consequences for management practices are discussed.

\section{Materials and Methods}

\section{Plant material}

Cirsium dissectum and Succisa pratensis were sampled at different locations throughout the Netherlands (see Fig. 1) in May and June 1996, except "Schiermonnikoog" (S), where C. dissectum was sampled in 1997 ( $S$. pratensis did not occur here). The

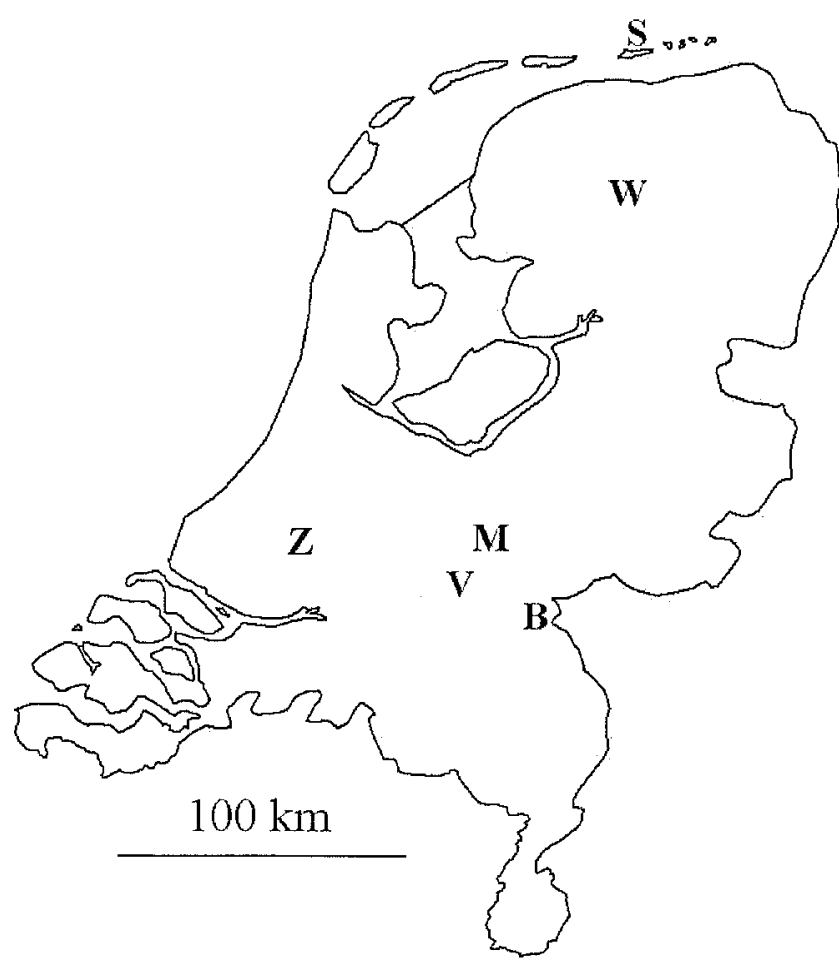

Fig. 1 Location of the populations in the Netherlands for both $C$. dissectum and S. pratensis plants. Bennekomse Meent (M) $52^{\circ} 04^{\prime} \mathrm{N}$, $5^{\circ} 36^{\prime} \mathrm{E}$, Zegveld/de Meije (Z) $52^{\circ} 08^{\prime} \mathrm{N}, 4^{\circ} 49^{\prime} \mathrm{E}$, De Bruuk (B), $51^{\circ} 46^{\prime} \mathrm{N}, 5^{\circ} 58^{\prime} \mathrm{E}$, Wynjeterper Schar/De Scharren (W) $53^{\circ} 04^{\prime} \mathrm{N}$, $6^{\circ} 10^{\prime} \mathrm{E}$, Schiermonnikoog/Kapenglop (S) $53^{\circ} 29^{\prime} \mathrm{N}, 6^{\circ} 10^{\prime} \mathrm{E}$. In (S) only C. dissectum was sampled. Reintroduction experiments were carried out at the "Veenkampen" (V) (51 $\left.{ }^{\circ} 99^{\prime} \mathrm{N}, 5^{\circ} 37^{\prime} \mathrm{E}\right)$, which is located $4 \mathrm{~km}$ southeast of the nearest source population (M).

populations were chosen because they occur in relatively undisturbed Junco-Molinion communities in nature conservation areas. The populations of these species are comprised of several hundreds to thousands of plants. Sampling consisted of a young leaf of 25-35 individual plants per population (M, W, $\mathrm{Z}$, B, and S samples). To avoid inclusion of more than one sample from any clone, samples were taken at least $10 \mathrm{~m}$ apart. Samples were frozen immediately in liquid $\mathrm{N}_{2}$, and stored at $-80^{\circ} \mathrm{C}$ until DNA extraction using the method of Fulton et al. $\left(1995^{[4]}\right)$.

\section{Reintroduction experiments}

In August 1996, seeds were collected from the "Bennekomse Meent" (M), "Zegveld" (Z), and "de Bruuk" (B) populations for both species, and also from the "Wynjeterper Schar" (W) population of $C$. dissectum. From each population, 200 - 500 flower heads were collected randomly throughout the field, avoiding multiple samples from what might be one clone. Flower heads were selected so that they were filled with seeds and at the correct ripening stage, which is easy to determine for $S$. pratensis but more difficult for $C$. dissectum. For $C$. dissectum, flower heads contained on average 5 - 10 seeds, for S. pratensis, flower heads contained $10-20$ seeds.

All flower heads from one population were combined, and seeds were mechanically cleaned, which removed part of the empty and non-viable seeds. In this way, seeds originating 
from one mother plant could not be distinguished, and certain mother plants may have contributed more seeds than others. This was considered to be a realistic situation, which may also occur in large-scale reintroduction experiments. In total, 2000 seeds were sown for each species on 16 separate, randomized plots at the experimental fields at the "Veenkampen" that autumn. Germination percentages (9-19\% for C. dissectum, 1 $13 \%$ for $S$. pratensis) were determined in June of the following year, 1997. For genetic analysis, 25 - 35 plants were sampled in the same month ( $\mathrm{m}^{\prime}, \mathrm{w}^{\prime}, \mathrm{z}^{\prime}$, and $\mathrm{b}^{\prime}$ samples).

An estimation of the variation between reintroductions from the same population was made by comparing the results with those of a reintroduction experiment carried out a year earlier. Here, seeds from approximately 100 flower heads of the M populations of $C$. dissectum as well as $S$. pratensis were collected, cleaned, and sown at experimental fields at the "Veenkampen" near Wageningen (see Fig. 1) in the fall of 1995. In June 1996, 25-35 plants that had germinated were sampled for genetic analysis, as above ( $\mathrm{m}^{0}$ sample).

\section{Genetic diversity}

The genetic diversity within and between the populations and their reintroduced populations was estimated using AFLP (Vos et al., $\left.1995^{[25]}\right)$. Primary template DNA was prepared in a onestep restriction-ligation reaction. Total genomic DNA (300 ng) was digested with $5 \mathrm{U}$ EcoRI and $5 \mathrm{U}$ MseI (Life Technologies) in $40 \mu \mathrm{l} 10 \mathrm{mM}$ Tris- $\mathrm{HCl}$ buffer, $10 \mathrm{mM}$ magnesium acetate, $50 \mathrm{mM}$ potassium acetate, $\mathrm{pH} 7.5$ for $1 \mathrm{~h}$ at $37^{\circ} \mathrm{C}$. Subsequently, $10 \mu \mathrm{l}$ of a ligation mixture containing $5 \mathrm{pmol}$ EcoRI adapter, $50 \mathrm{pmol} \mathrm{MseI} \mathrm{adapter} \mathrm{(Isogen)} \mathrm{and} 2$ U T4 DNA ligase (Life Technologies) in the same buffer as before but with $0.4 \mathrm{mM}$ ATP added. This restriction-ligation reaction was incubated for $3 \mathrm{~h}$ at $37^{\circ} \mathrm{C}$. The resulting primary template was diluted to $200 \mu \mathrm{l}$ with $10 \mathrm{mM}$ Tris-HCl, $0.1 \mathrm{mM}$ EDTA pH 8.0 and stored at $-20^{\circ} \mathrm{C}$ until use. AFLP fingerprints were made using a twostep PCR amplification. The first step (preamplification) was performed on a primary template using a primer pair based on the sequences of the EcoRI and MseI adapter with one additional selective nucleotide at the $3^{\prime}$ end. Amplification reactions $(20 \mu \mathrm{l})$ contained, $5 \mu \mathrm{l}$ primary template, $30 \mathrm{ng}$ of each primer, $0.4 \mathrm{U} \mathrm{Taq}$ polymerase, $0.2 \mathrm{mM}$ of all four dNTPs, $10 \mathrm{mM}$ Tris- $\mathrm{HCl} \mathrm{pH} 8.3,50 \mathrm{mM} \mathrm{KCl}, 1.5 \mathrm{mM} \mathrm{MgCl}_{2}$ and $0.001 \%$ gelatine. Preamplification products were diluted 20 -fold with $10 \mathrm{mM}$ Tris-HCl, $0.1 \mathrm{mM}$ EDTA pH 8.0 and used as template in the second amplification reaction. This second step (selective amplification) was performed with primers having three selective nucleotides each. Amplification conditions were as described above, with the exception that only $5 \mathrm{ng}$ of ${ }^{33} \mathrm{P}$-labelled EcoRI primer were used. Standard cycling conditions were: 1 cycle $94{ }^{\circ} \mathrm{C}$ for $30 \mathrm{~s}, 65^{\circ} \mathrm{C}$ for $30 \mathrm{~s}$, and $72{ }^{\circ} \mathrm{C}$ for $1 \mathrm{~min}$. The $65^{\circ} \mathrm{C}$ annealing temperature was subsequently reduced by $0.7^{\circ} \mathrm{C}$ for the next 12 cycles, and continued at $56^{\circ} \mathrm{C}$ for the remaining 23 cycles. Reaction products were loaded on a $6 \%$ polyacrylamide gel (Sequagel-6, Biozym) in $1 \times$ TBE electrophoresis buffer using a SequiGen $38 \times 50 \mathrm{~cm}$ gel apparatus (BioRad Laboratories). Gels were dried on Whatmann 3MM paper, and X-ray films (Kodak X-OMAT) were exposed for 1-3 weeks at room temperature.

In order to identify primer combinations that yielded wellscorable polymorphisms for either species, approximately 100 combinations of EcoRI/MseI primers with three selective bases each, were tested on three samples taken from three different populations. In general, it was difficult to find primer pairs that amplified more than 5-10 polymorphic bands among the three samples of the $C$. dissectum populations. It was somewhat easier for the $S$. pratensis samples. After preselecting three primer pairs for each of the species, 39 scorable polymorphic bands were amplified for $C$. dissectum (using primer combinations E32-M44, E33-M38, and E37-M43), and 50 for $S$. pratensis (using the combinations E35-M58, E37M48, and E37-M52). The primer sequences are: E32: 5'GACTGCGTACCAATTCAAC-3'; E33: 5'-GACTGCGTACCAATTCAAG-3'; E35: 5'-GACTGCGTACCAATTCACA-3'; E37: 5'GACTGCGTACCAATTCACG-3'; M38: 5'-GATGAGTCCTGAGTAAACT-3'; M43: 5'-GATGAGTCCTGAGTAAATA-3'; M44: 5'GATGAGTCCTGAGTAAATC-3'; M48: 5'-GATGAGTCCTGAGTAACAC-3'; M52: 5'-GATGAGTCCTGAGTAACCC-3'; M58: 5'-GATGAGTCCTGAGTAACGT-3'. For each primer combination polymorphic bands were recorded and given a serial number. Presence (1) or absence (0) of each polymorphic band was scored for all genotypes. Data were analyzed using Genstat 5.

AFLP yield dominant data. For the natural populations, allele frequencies can be deduced from these dominant data, but only if it is assumed that the populations are in Hardy-Weinberg equilibrium (Lynch and Milligan, 1994[15]). This is not a valid assumption for the reintroduced populations. Therefore, similarities were used. Similarity for each pair of samples was calculated using the simple matching coefficient $s=(a+b)$ / $(a+b+c)$, where $a$ denotes the number of markers for which, in both individuals, a band is present; $b$ denotes the number of markers for which, in both individuals, a band is absent; and $c$ denotes the number of markers for which, in only one of the individuals, a band is present. A principal coordinate analysis (PCO) was carried out based on the similarity matrix (as in Arens et al., 1998 $\left.{ }^{[1]}\right)$. Assignment tests were done by assigning each consecutive plant to the single most similar individual, and determining to which population it belongs. Significance of differences in assignment scores was tested by comparison to the results of 100 simulations after randomizing population positions of all individual plants.

A $\mathrm{F}_{s t}$ analog for dominant data was estimated as $\Phi_{s t}=\sigma_{b}{ }^{2}$ | $\left(\sigma_{b}^{2}+\sigma_{c}^{2}\right)$, the weighted average of the single-locus ratio estimator defined by Reynolds et al. (1983[21]), using the estimate of the variance component due to band frequency differences among populations $\left(\sigma_{b}^{2}\right)$, and the estimate of the total variation $\left(\sigma_{b}^{2}+\sigma_{c}^{2}\right)$, across all bands (as in Grashof-Bokdam et al., $\left.1998^{[7]}\right)$. Significance of the calculated $\Phi_{s t}$ was tested by comparison with the results of 1000 simulations after randomizing population positions of all individual plants across the relevant grasslands (e.g., Hamilton, 1997[11]).

Differences between the number of polymorphic bands in source and reintroduced populations were tested with a T-test. Figures given are averages \pm SE. Reintroductions from two source populations were simulated using all possible combinations of the first and second group of 15 plants from each population.

\section{Growth room experiments}

Seeds of $C$. dissectum were collected from a number of plants of M, W and Z populations in August 1997. After germination, plants were grown in a growth room under the following con- 
ditions: irradiance at average plant height: $300 \mu \mathrm{mol} \times \mathrm{m}^{-2} \times \mathrm{s}^{-2}$ supplied by 400 W HPI lamps; light period: 14 h; day and night temperature $20^{\circ} \mathrm{C}$; relative humidity $75 \%$. Plants were grown in "free-draining" pots (height $40 \mathrm{~cm}$, diameter $11 \mathrm{~cm}$ ) filled with quartz sand $(0.7-1.25 \mathrm{~mm})$. Six hundred ml nutrient solution ( $\mathrm{pH} 5.0 ; 1.5 \mathrm{mM} \mathrm{KNO}_{3}, 3 \mathrm{mM} \mathrm{Ca}\left(\mathrm{NO}_{3}\right)_{2}, 1 \mathrm{mM} \mathrm{MgSO}_{4}$, $1 \mathrm{mM} \mathrm{KH} \mathrm{PO}_{4}, 0.25 \mathrm{mM} \mathrm{K}_{2} \mathrm{SO}_{4}, 0.015 \mathrm{mM}$ Fe-EDTA, $0.02 \mathrm{mM}$ $\mathrm{H}_{3} \mathrm{BO}_{3}, 0.02 \mathrm{mM} \mathrm{MnSO}_{4}, 1 \mu \mathrm{M} \mathrm{ZnSO}, 0.5 \mu \mathrm{M} \mathrm{Na} \mathrm{ZnO}_{4}$ and $0.5 \mu \mathrm{M} \mathrm{CuSO}_{4}$ ) was added automatically each day to the pots. Preliminary experiments showed that the nutrient solution was equally distributed over the quartz sand column. In the presence of plants, no indication of drought was observed just before the next addition of nutrient solution. The daily quantum input ( $15 \mathrm{~mol} \times \mathrm{m}^{-2} \times$ day $^{-1}$ ) allows the plants to grow near their maximum rate (Poorter and Van der Werf, 1988 ${ }^{[18]}$ ). Two harvests were performed with 34 plants per population per harvest. At the first harvest, average total plant dry weight of the seedlings was $68 \mathrm{mg}$ and did not differ significantly between populations. The second harvest was $13(\mathrm{M})$ or 14 days (W and $\mathrm{Z}$ populations) later. Relative growth rate and net assimilation rate were calculated for the period between the two harvests, according to standard procedures (Hunt, $\left.1982^{[13]}\right)$. All other values of the parameters given in this paper are averages of the two harvests. For chemical analyses of leaves and roots, 24 plants from the second harvest were pooled into six samples. In each leaf sample carbon, total nitrogen, nitrate, phosphorus, potassium, ash, and ash alkalinity were determined. Due to insufficient plant material, roots were only analyzed for N, P and K. Differences in plant traits between populations were tested with a Student-NewmanKeuls test after a one-way analysis of variance using Genstat 5.

\section{Results}

\section{Diversity among populations across The Netherlands}

To estimate which part of the genetic diversity was distributed among populations, $\Phi_{s t}$ was calculated. Values were 0.108 and 0.100 for $C$. dissectum and $S$. pratensis, respectively (Table $\mathbf{1}$ ), indicating some differentiation of the populations. As expected for outcrossing species, most of the variation was present within populations. The differences between populations were based on band frequency differences. Even though some bands were absent in certain populations, and other bands were present throughout a population, in no case was one band absent in a population and present in all plants in another population. Band frequency differences were significant for only a small number of bands. As a consequence of limited distinction, in terms of band presence and frequency, a PCO analysis yielded hardly any distinction between the different populations. For all plants of the populations, the first two axes explained only a limited part of the variation (10.2\% and $7.8 \%$, respectively, for C. dissectum; $7.5 \%$ and $5.9 \%$ for $S$. pratensis) (not shown).

With regard to ecophysiological traits, measured under controlled conditions in a growth chamber, the $\mathrm{W}$ and $\mathrm{Z}$ populations of $C$. dissectum showed the greatest similarity in the ecophysiological traits measured (Table 2). Only leaf mass ratio (LMR) differed significantly between these two populations. The $\mathrm{M}$ population differed from the $\mathrm{W}$ and $\mathrm{Z}$ populations in 4-5 out of 6 traits. Hardly any difference was observed in chemical composition (not shown).
Table 1 Genetic differentiation among populations and the influence of reintroduction

\begin{tabular}{lll}
\hline Comparison & \multicolumn{2}{c}{$\Phi_{\text {st }}$ values } \\
& $\begin{array}{l}\text { Cirsium } \\
\text { dissectum }\end{array}$ & $\begin{array}{l}\text { Succisa } \\
\text { pratensis }\end{array}$ \\
\hline $\begin{array}{l}\text { among source populations } \\
(\mathrm{n}=4-5)\end{array}$ & $0.108^{*}$ & $0.100^{*}$ \\
$\begin{array}{l}\text { among reintroduced populations } \\
(\mathrm{n}=3-4)\end{array}$ & $0.135^{*}$ & $0.138^{*}$ \\
$\begin{array}{l}\text { between } \mathrm{M} \text { and its reintroduced } \\
\text { population } \mathrm{m}^{\prime}(\mathrm{n}=2)\end{array}$ & $0.032^{*}$ & $0.012^{*}$ \\
$\begin{array}{l}\text { between } \mathrm{W}^{*} \text { and its reintroduced } \\
\text { population } \mathrm{w}^{\prime}(\mathrm{n}=2)\end{array}$ & $0.035^{*}$ & $\mathrm{ND}$ \\
$\begin{array}{l}\text { between } \mathrm{Z} \text { and its reintroduced } \\
\text { population } \mathrm{z}^{\prime}(\mathrm{n}=2)\end{array}$ & 0.023 & $0.054^{*}$ \\
$\begin{array}{l}\text { between } \mathrm{B} \text { and its reintroduced } \\
\text { population } \mathrm{b}^{\prime}(\mathrm{n}=2)\end{array}$ & $0.101^{*}$ & $0.039^{*}$ \\
$\begin{array}{l}\text { between the two reintroduced } \mathrm{M} \\
\text { populations } \mathrm{m}^{\prime} \text { and } \mathrm{m}^{0}(\mathrm{n}=2)\end{array}$ & 0.008 & $0.032^{*}$ \\
\hline
\end{tabular}

* significantly different at $p<0.05$

ND: not determined (no reintroduction)

Table 2 Mean values of relative growth rate (RGR; $\mathrm{mg} \mathrm{g}^{-1}$ plant day $\left.{ }^{-1}\right)$, net assimilation rate (NAR, $\mathrm{g} \mathrm{m}^{-2}$ day $^{-1}$ ), leaf area ratio (LAR, $\mathrm{m}^{2} \mathrm{~kg}^{-1}$ leaf), specific leaf area (SLA, $\mathrm{m}^{2} \mathrm{~kg}^{-1}$ leaf), leaf mass ratio (LMR, g leaf $\mathrm{g}^{-1}$ plant) and root mass ratio (RMR, g root $\mathrm{g}^{-1}$ plant) for three Cirsium dissectum populations. Data expressed on a dry weight basis. Means with the same letter were not significantly different $(p>0.05)$

\begin{tabular}{lllllll}
\hline Population & RGR & NAR & LAR & SLA & LMR & RMR \\
\hline M & $117^{\mathrm{a}}$ & $9.7^{\mathrm{a}}$ & $12.5^{\mathrm{a}}$ & $20.9^{\mathrm{a}}$ & $0.60^{\mathrm{a}}$ & $0.32^{\mathrm{a}}$ \\
W & $131^{\mathrm{b}}$ & $10.6^{\mathrm{b}}$ & $13.2^{\mathrm{ab}}$ & $20.5^{\mathrm{a}}$ & $0.64^{\mathrm{b}}$ & $0.28^{\mathrm{b}}$ \\
Z & $136^{\mathrm{b}}$ & $10.6^{\mathrm{b}}$ & $13.7^{\mathrm{b}}$ & $20.2^{\mathrm{a}}$ & $0.67^{\mathrm{c}}$ & $0.26^{\mathrm{b}}$ \\
\hline
\end{tabular}

Thus, the population genetic markers show small but significant differences among source populations. Some of the ecophysiological data also show differences. Whether these are significant in terms of reintroduction was studied further using the genetic markers.

\section{Genetic diversity after reintroduction}

Reintroduction of plants from different populations on separate experimental fields in "De Veenkampen" near Wageningen resulted in small populations $\left(150-250\right.$ plants in the $\mathrm{m}^{0}$ populations in 1996; 30-200 plants each in the $\mathrm{m}^{\prime}, \mathrm{w}^{\prime}, \mathrm{s}^{\prime}$, and $b^{\prime}$ populations after the wet winter and spring of 1997) that were sampled in the following spring. To determine whether the genetic composition of the reintroduced populations was changed compared to corresponding source populations, we compared the pairs of populations for both species. For this, we employed $\Phi_{s t}$, calculated on the basis of variance in band frequencies, as a measure of genetic differentiation. Small but significant differences were found in all but one pairwise comparisons of source and reintroduced populations (Table $\mathbf{1}$ ). The $\Phi_{s t}$ value among the reintroduced populations as a group, however, was not reduced when compared to the group of source populations. 

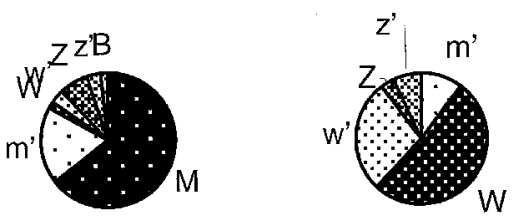

from $m$ ' to

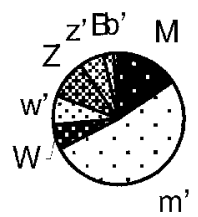

b

from $M$ to

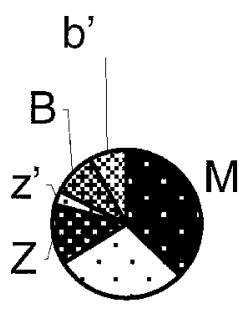

$m^{\prime}$

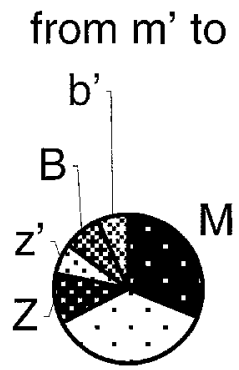

$\mathrm{m}^{\prime}$

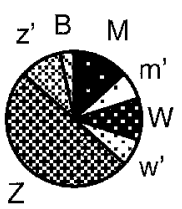

from $z^{\prime}$ to

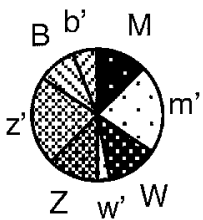

\section{from $B$ to}

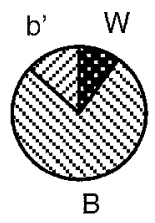

from b' to

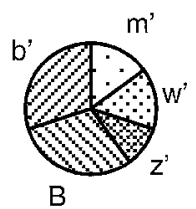

Fig. 2 Assignment of $C$. dissectum (a) and $S$. pratensis (b) plants to the population containing the most similar individual, across source (M-W-Z-B) and reintroduced $\left(\mathrm{m}^{\prime}-\mathrm{w}^{\prime}\right.$ $\left.z^{\prime}-b^{\prime}\right)$ populations, where $m^{\prime}$ is the reintroduced population of $M, W^{\prime}$ of $W$, etc. The population from which the plants were taken is indicated above the corresponding pie chart. Proportions of plants assigned to the different source and reintroduced populations are indicated by the size of the corresponding part of the pie. As far as source plants are being assigned to source populations, or reintroduced plants to reintroduced populations, the results are the same as in assignments involving only source or only reintroduced populations (which are not shown). The percentages of assignments to different groups are slightly different because of source plants now assigned to reintroduced populations (and vice versa).

\section{from $B$ to}

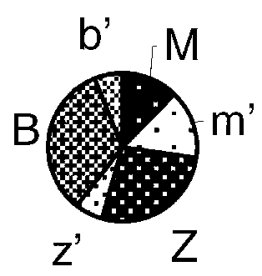

$$
\text { from z' to }
$$

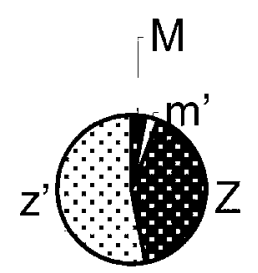

\section{from b' to}

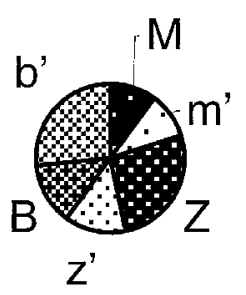

The sampling error in this type of reintroduction experiment was estimated by comparing two reintroductions from the M population: one in $1996\left(\mathrm{~m}^{0}\right)$ and one together with the other populations in $1997\left(\mathrm{~m}^{\prime}\right)$. The $\Phi_{s t}$ between $\mathrm{m}^{0}$ and $\mathrm{m}^{\prime}$ was only 0.008 for $C$. dissectum, which is not significantly different from zero (Table 1). For the two reintroductions of $S$. pratensis, $\Phi_{s t}$ was 0.032 , which is significantly different from zero, and comparable to the genetic differentiation between source and reintroduced populations observed in some reintroductions of $S$. pratensis.
How important are the small genetic differences between populations?

The question is to what extent the small genetic differences that we have measured among populations, represent genetically distinct genotypes. To answer this, we used assignment tests in which each plant of a population was matched to its most genetically similar plant, and the population that this plant belonged to was scored. We performed this test with several combinations of source and reintroduced populations. Since the general tendencies are the same, we show in Fig. 2 only the most comprehensive one (described in the next sec- 
Table 3 Genetic variation present within source and reintroduced populations or combinations thereof

\begin{tabular}{lll}
\hline Group & \# of polymorphic bands & \\
\hline & $\begin{array}{l}\text { Cirsium dissectum } \\
\text { (populations M, W, Z, B) }\end{array}$ & $\begin{array}{l}\text { Succisa pratensis } \\
\text { (populations M, Z, and B) }\end{array}$ \\
any source population & $28-32$ & $36-40$ \\
any two source populations & $31-36$ & $40-45$ \\
all source populations together & 40 & 47 \\
& & Succisa pratensis \\
(populations $\mathrm{m}^{\prime}, \mathrm{z}^{\prime}, \mathrm{b}^{\prime}$ )
\end{tabular}

tion). Between different combinations of populations the precise assignment proportions vary since every plant can be assigned only once. The figures mentioned and the statistical tests are always from the proper assignment test.

Among the source populations ( $\mathrm{M}, \mathrm{W}, \mathrm{Z}$, and $\mathrm{B})$, source population plants were assigned to their own population with varying success, but generally with a level of correct assignment that is significantly higher than would be expected by chance: $75 \%$ for C. dissectum, $62 \%$ for $S$. pratensis. Nevertheless, between $1 / 4$ and $1 / 3$ of the plants were assigned to other populations; these genotypes would fit in other populations at least as well. This indicates that the source populations were composed of plants that were genetically distinct, but only to a limited degree.

Correct assignments are somewhat less frequent for the reintroduced populations. The correct assignment percentage of C. dissectum reintroduced plants among reintroduced populations was $64 \%$, and for $S$. pratensis it was $52 \%$, which was still significantly higher than would be expected by chance. The difference in correct assignments, when comparing any population with its reintroduced population, was never significant, except for the $\mathrm{M}$ and $\mathrm{m}^{\prime}$ populations of $C$. dissectum. Again, it must be noted that a fair amount, between $1 / 3$ and $1 / 2$ of the plants, were most similar to individuals from other populations. Thus, the reintroduced populations in general do not diverge much from the source populations.

\section{Are the reintroduced populations as genetically diverse as the source populations?}

For assessing the extent of genetic diversity within populations, we used two measures. First, when comparing both source and reintroduced populations in one assignment test (Fig. 2), it became clear that, on average, almost as many plants were assigned to the reintroduced populations as to the source populations, for $C$. dissectum as well as for $S$. pratensis. Since the test searches for the highest similarity with any plant in any population, it follows from the results that the reintroduced populations contain almost the same extent of diversity among plants as the source populations. Thus, it appears that they can be regarded as populations in their own right.

Second, we looked at the number of polymorphic bands. For $C$. dissectum, each of the source populations contained between 28 and 32 (average $30.2 \pm 0.9, \mathrm{n}=4$ ) polymorphic bands (i.e., bands with a population frequency f, $0<\mathrm{f}<1$ ) among the 40 bands that were polymorphic in the total study (Table 3 ). Within the reintroduced populations, between 26 and 30 bands were polymorphic (average $28.5 \pm 1.5, \mathrm{n}=4$ ). For $S$. pratensis, we actually see slightly more polymorphic bands in the sample from the reintroduced populations $(37.7 \pm 1.8$ versus $39.3 \pm 1.2$ of 50 polymorphic bands, $n=3, p>0.05$ ), always due to bands with very low or very high frequencies, whose polymorphism was by chance not included in the source population sample.

Calculation of number of polymorphic bands also allows testing of whether reintroduction from two source populations would have yielded more genetic variation than reintroduction from one population. For this, a reintroduction from two source populations was simulated by sampling at random half the number of plants from one reintroduced population, combining it with half the plants from another reintroduction, and then calculating the number of polymorphic bands in the resulting simulated reintroduced population. The figures (Table 3) show that reintroduction using two source populations results in more polymorphic bands than reintroduction from one population. The differences were significant (S. pratensis, one reintroduction contains $39.3 \pm 1.2$ [ $\mathrm{n}=3$ ], while reintroduction from two populations contains $43.7 \pm 0.6[\mathrm{n}=12]$ polymorphic bands, $p<0.05$ ) or marginally significant $(C$. dissectum, one reintroduction contains $28.5 \pm 1.5[n=4]$ polymorphic bands, while combinations of two reintroductions contain $32.1 \pm 0.3[n=24]$ polymorphic bands, $p=0.05$ ).

\section{Selection or drift: do the reintroduced populations resemble one source population more than others?}

The genetic changes taking place during reintroduction may be the result of founder effects, due to the small number of seeds involved. However, they might also be due to (some) selection for a genetic composition that is better suited for the growing conditions in the reintroduction site. In the latter case, it is possible that the genetic composition would shift in a certain direction, and most likely towards that of the "Bennekomse Meent", which is only $4 \mathrm{~km}$ away in the same river valley. However, the $\Phi_{s t}$ value among the reintroduced populations as a group was not reduced when compared to the group of source populations, so this does not point to any selection. Also, the $C$. dissectum reintroduced population from the "Bennekomse Meent" and the original population differ as much 
from each other $\left(\Phi_{s t} 0.032\right)$ as the other pairs of populations. For S. pratensis, the difference of 0.012 is somewhat smaller than for the other pairs (Table $\mathbf{1}$ ).

If reintroduced populations would somewhat more resemble the $\mathrm{M}$ population, then one would expect that in the assignment test the $\mathrm{w}^{\prime}, \mathrm{z}^{\prime}$ and $\mathrm{b}^{\prime}$ reintroduced populations attract more $\mathrm{M}$ and $\mathrm{m}^{\prime}$ plants than the $\mathrm{W}, \mathrm{Z}$ and $\mathrm{B}$ populations. This was not the case (Fig. 2).

\section{Discussion}

\section{Differences among populations}

In accordance with the fact that both $C$. dissectum and S. pratensis are outcrossers, most of the genetic variation was found within populations. The genetic differences among populations of $C$. dissectum and S. pratensis in the Netherlands were small ( $\Phi_{s t}$ of around 0.1) but significantly different from zero. The differences concerned variation in band frequencies, rather than the occurrence of unique bands. The assignment tests showed that, although the largest fraction of plants were assigned to the source population, between $1 / 4$ and $1 / 2$ of the plants of a given population matched most closely a plant in another population. Thus, genetic differentiation in terms of distinct genotypes was very limited. It should be noted that the geographical distances among source populations were also not large, and did not span any major discontinuity in species presence.

Diversity in neutral markers, such as AFLP, does not necessarily reflect differences in functional traits (Booy et al., 2000 ${ }^{[3]}$ ). However, also in ecophysiological traits for the vegetative growth phase, as analyzed for three populations of $C$. dissectum under controlled conditions, only small differences or no differences at all were found between $\mathrm{W}$ and $\mathrm{Z}$ populations. The M population showed some differences (Table 2 ), but the variation among species from typical nutrient-poor sites (Van der Werf et al., $1993^{[23]}, 1998^{[24]}$ ) is far greater than the small differences among populations of $C$. dissectum observed in this study. Whether the variation within populations is genetically determined cannot be inferred from our growth analyses. Gordon and Rice $\left(1998^{[6]}\right)$ found genetic differentiation among populations of wiregrass, but reciprocal transplant experiments did not provide evidence for local adaptation. Helenurm $\left(1998^{[12]}\right)$ found that seeds from a small source population of Lupinus guadalupensis performed worse than seeds from two larger populations in reciprocal transplant experiments, regardless of the reintroduction site. This is, perhaps, due to some inbreeding in the smaller population.

\section{Differences upon reintroduction}

When using these populations for reintroduction, we find small but significant changes in genetic composition between source and reintroduced populations, as measured by pairwise $\Phi_{s t}$. As a result, plants from the reintroduced populations are assigned more frequently to the reintroduced population than to the corresponding source population, i.e. they resemble each other somewhat more than plants from their population of origin. It should be noted that the changes between source and reintroduced populations may partly be due to sampling effects. The magnitude of this effect, estimated by re- introducing M populations twice, was $\Phi_{s t} 0.008-0.032$ for replicate reintroductions, which is lower than the average differentiation between source and reintroduced populations. The remaining differences are most probably due to founder effects in the first generation reintroduced plants. Genetic drift in successive generations had not occurred yet, since the reintroduced plants had not flowered and set seed.

When comparing all populations together, nearly all reintroduced populations resembled their own source population more than any other source population (see the assignments in Fig. 2). There was no trace of a shift of genetic composition towards one of the source populations, which could occur if some of the AFLP fragments were under indirect selection through "hitch-hiking" with loci that are under selective pressure. AFLP markers are considered to be neutral markers, so they are not useful to estimate selection pressure. Furthermore, our experimental set-up does not allow a correct comparison of selection pressure. Seeds were introduced on bare soil where the topsoil layer was removed in the year of seed introduction. One year after this sod removal, several species, including the reintroduced, indeed re-established, but at a very low abundance. This indicates that a selective pressure due to competition between plants of different species and the reintroduced plants was not present in our system. Therefore, it cannot be excluded that in the presence of competing plants, i.e., introducing seeds in fully established vegetation, selection towards a certain population or a certain shift in genetic composition would occur. Furthermore, we studied only the establishment of juvenile plants from seeds collected from mature plants in other populations. To fully evaluate the importance of the source material used for reintroduction, the genetic composition of the next generation, i.e., the seeds of the reintroduced plants, should also be considered, since these will be the first to have completed a full life cycle at the reintroduction plot.

\section{How to reintroduce}

When the original population in an area where we want to reintroduce has disappeared, we will never know whether a reintroduced population is "identical" or performs "the same". The question is, how to proceed to limit the risk of introducing a population that is not well adapted or not well prepared for the future. As discussed above, we have no proof for significant genetic differences among populations of the species studied. On the other hand, the quantity of genetic diversity within populations should be sufficient to allow the generation of plants with different combinations of traits (Booy et al., $2000^{[3]}$; van Groenendael et al., 1998 ${ }^{[9]}$ ). In outcrossing species, such as C. dissectum and S. pratensis, most of the genetic variation is contained within populations rather than between populations. This means that reintroduction should take care not to loose this variation. Therefore, it is important to monitor the occurrence of genetic drift by studying also the next generations, i.e., the plants that establish themselves from seeds produced by the reintroduced plants, and their progeny. The fact that the reintroduced species are perennials may reduce the occurrence of genetic drift.

Our data indicate that, due to the small number of plants actually reintroduced, the reintroduced populations have less polymorphic bands compared to their source populations. It may 
be that if one introduces a very large number of seeds from a very large number of parental plants, genetic changes can be minimized. However, this may not always be feasible, or may be too much of a drain for the source population (van Groenendael et al., 1998 ${ }^{[9]}$ ). Also, if weather conditions are not favourable, as in our study in the winter of 1997, only a small number of plants may be able to establish themselves. Our calculations show that reintroduction of a limited number of seeds from two populations yields more polymorphic bands than reintroduction of the same number of seeds, but taken from only one population. This is due to the fact that each of the possible source populations has slightly different allele frequencies. Even with a limited number of seeds, it appears possible to capitalize on the existence of these differences to "catch" more diversity. Therefore, other things being equal, reintroduction from more than one source population appears the safest approach.

\section{Acknowledgements}

This project was funded by the Ministry of Agriculture, Nature and Fisheries of The Netherlands. We thank the State Forestry Commision (SBB) and Natuurmonumenten (NM) for permission to sample in their nature reserves: De Bruuk, De Bennekomse Meent, De Scharren (Wynjeterper Schar) and De Meye in Zegveld (SBB) and De Kapenglop on Schiermonnikoog (NM), and Joop Ouborg, Hans de Kroon and Ineke Booy for critically reading of the manuscript.

\section{References}

${ }^{1}$ Arens, P., Coops, H., Jansen, J., and Vosman, B. (1998) Molecular genetic analysis of Black poplar (Populus nigra L.) along Dutch rivers. Molecular Ecology 7,11 - 18.

2 Berendse, F., Oomes, M. J. M., Altena, H. J., and De Visser, W. (1994) A comparative study of nitrogen flows in two similar meadows affected by different groundwater levels. Journal of Applied Ecology $31,40-48$.

${ }^{3}$ Booy, G., Hendriks, R. J. J., Smulders, M. J. M., Van Groenendael, J. M., and Vosman, B. (2000) Genetic diversity and the survival of populations. Plant biol. 2, 379-395.

${ }^{4}$ Fulton, T. M., Chunwongse, J., and Tanksley, S. D. (1995) Microprep protocol for extraction of DNA from tomato and other herbaceous species. Plant Molecular Biology Reporter 13, 207-209.

${ }^{5}$ Geerts, R. H. E. M., Ketelaars, J. J. M. H., Oomes, M. J. M., Korevaar, H., and van der Werf, A. K. (1996) Reintroduction of grassland species. In Annual Report 1995. Wageningen: Research Institute for Agrobiology and Soil Fertility (AB-DLO), pp. 65-68.

${ }^{6}$ Gordon, D. R. and Rice, K. J. (1998) Patterns of differentiation in wiregrass (Aristida beyrichiana): implications for restoration efforts. Restoration Ecology 6, 166-174.

${ }^{7}$ Grashof-Bokdam, C. J., Jansen, J., and Smulders, M. J. M. (1998) Dispersal patterns of Lonicera periclymenum determined by genetic analysis. Molecular Ecology 7, 165 - 174.

${ }^{8}$ Grime, J. P. and Hunt, R. (1975) Relative-growth-rate: Its range and adaptive significance in a local flora. Journal of Ecology 63, 393 422.

${ }^{9}$ van Groenendael, J. M., Ouborg, N. J., and Hendriks, R. J. J. (1998) Criteria for the reintroduction of plant species. Acta Botanica Neerlandica 47, 3-13.

${ }^{10}$ Jones, A. T. and Hayes, M. J. (1999) Increasing floristic diversity in grasslands: the effects of management regime and provenance on species introduction. Biological Conservation 87, 381-390.

${ }^{11}$ Hamilton, M. B. (1997) Genetic fingerprint-inferred population subdivision and spatial genetic tests for isolation by distance and adaptation in the coastal plant Limonium carolinianum. Evolution $51,1457-1468$.

${ }^{12}$ Helenurm, K. (1998) Outplanting and differential source population success in Lupinus guadalupensis. Conservation Biology 12, $118-127$.

${ }^{13}$ Hunt, R. (1982) Plant Growth Curves. The Functional Approach to Plant Growth Analysis. London: E. Arnold.

${ }^{14}$ Lambers, H., Poorter, H., and van Vuuren, M. M. I. (1998) Inherent Variation in Plant Growth. Physiological mechanisms and Ecological Consequences. Leiden: Backhuys Publishers.

${ }^{15}$ Lynch, M. and Milligan, B. G. (1994) Analysis of population genetic structure with RAPD markers. Molecular Ecology 3, 91 - 99.

${ }^{16}$ Nagy, E. S. (1997) Selection for native characters in hybrids between two locally adapted plant subspecies. Evolution 51, 14691480.

17 Oomes, M. J. M., Olff, H., and Altena, H. J. (1996) Effects of vegetation management and raising the water table on nutrient dynamics and vegetation change in a wet grassland. Journal of Applied Ecology 33, 576-588.

18 Poorter, H. and Van der Werf, A. (1998) Is inherent variation in RGR determined by LAR at low irradiance and by NAR at high irradiance? A review of herbaceous species. In Inherent Variation in Plant Growth. Physiological mechanisms and Ecological Consequences (Lambers, H., Poorter, H., and Van Vuuren, M. M. I., eds), Leiden: Backhuys Publishers, pp. 309-336.

${ }^{19}$ Prins, A. H., Dijkstra, G. A., and Bekker, R. M. (1998) Feasibility of target communities in a Dutch brook valley system. Acta Botanica Neerlandica 47, $71-88$.

${ }^{20}$ Pywell, R., Peel, S., Hopkins, A., and Bullock, J. (1997) Multi-site experiments on the restoration of botanically diverse grasslands in ESAS. In Grassland management in the "Environmentally Sensitive Areas". Occasional Symposium,Vol. 32 (Sheldrick, B. D., ed.), British Grassland Society, pp.160-165.

${ }^{21}$ Reynolds, J., Weir, B. S., and Cockerham, C. C. (1983) Estimation of the coancestry coefficient: basis for a short-term genetic distance. Genetics 105, 767-779.

${ }^{22}$ Smulders, M. J. M., van de Wiel, C., Arens, P., and Vosman, B. (2000) The use of molecular markers for the characterisation of biodiversity and the study of ecological processes. Focus on Biotechnology, in press.

${ }^{23}$ van der Werf, A., van Nuenen, M., Visser, A. J., and Lambers, H. (1993) Contribution of physiological and morphological plant traits to a species' competitive ability at high and low nitrogen supply: a hypothesis for inherently fast- and slow-growing monocotyledonous species. Oecologia 94, 434-440.

${ }^{24}$ van der Werf, A., Geerts, R. H. E. M., Jacobs, F. H. H., Korevaar, H., Oomes, M. J. M., and de Visser, W. (1998) The importance of relative growth rate and associated traits for competition between species during vegetation succession. In Inherent Variation in Plant Growth. Physiological mechanisms and Ecological Consequences (Lambers, H., Poorter, H., and van Vuuren, M. M. I., eds.), Leiden: Backhuys Publishers, pp. 489-502.

${ }^{25}$ Vos, P., Hogers, R., Bleeker, M., Reijans, M., van de Lee, T., Hornes, M., Frijters, A., Pot, J., Peleman, J., Kuiper, M., and Zabeau, M. (1995) AFLP: A new technique for DNA fingerprinting. Nucleic Acids Research 23, 4407-4414.

\section{J. M. Smulders}

Plant Research International

P. O. Box 16

6700 AA Wageningen

The Netherlands

E-mail: m.j.m.smulders@plant.wag-ur.nl

Section Editor: R. Aerts 